\title{
Jacques Misan-Montefiore, Venise des voyageurs romantiques français
}

\section{Michel Arrous}

\section{(2) OpenEdition}

1 Journals

\section{Édition électronique}

URL : https://journals.openedition.org/studifrancesi/39491

DOI : 10.4000/studifrancesi.39491

ISSN : 2421-5856

Éditeur

Rosenberg \& Sellier

\section{Édition imprimée}

Date de publication : 1 décembre 2004

Pagination : 381

ISSN : 0039-2944

\section{Référence électronique}

Michel Arrous, " Jacques Misan-Montefiore, Venise des voyageurs romantiques français ", Studi Francesi [En ligne], 143 (XLVIII | II) | 2004, mis en ligne le 30 novembre 2015, consulté le 19 mai 2021. URL : http://journals.openedition.org/studifrancesi/39491; DOI : https://doi.org/10.4000/studifrancesi. 39491

Ce document a été généré automatiquement le 19 mai 2021.

\section{(c) (†) $\ominus$}

Studi Francesi è distribuita con Licenza Creative Commons Attribuzione - Non commerciale - Non opere derivate 4.0 Internazionale. 


\title{
Jacques Misan-Montefiore, Venise des voyageurs romantiques français
}

\author{
Michel Arrous
}

\section{RÉFÉRENCE}

JACQUES MISAN-MONTEFIORE, Venise des voyageurs romantiques français, Moncalieri, C.I.R.V.I., 2000, pp. 185

1 Après les recueils collectifs publiés par A. Zorzi et E.Kanceff, J.Misan-Montefiore a choisi d'étudier la vision romantique de Venise ou, plutôt, d'analyser la perception de son identité qu'en eurent les romantiques français, eux aussi fascinés comme leurs prédécesseurs depuis la Renaissance. L'intérêt de ce travail qui d'ailleurs poursuit l'enquête sur L'Eau, le rêve et le temps. Venise vue par les voyageurs français de 1850 à 1920 (Moncalieri, C.I.R.V.I.., 2003) réside d'abord dans l'étendue des dépouillements: récits d'auteurs célèbres (Staël, Sand, Gautier, Stendhal, Musset), mais aussi de romanciers ou de poètes secondaires, d'auteurs de guides fameux (Valery, ce «benêt emphatique», au jugement de Stendhal), ou de voyageurs connus comme Custine, Ampère, L. Simond, R. de Beauvoir, A. Jal, Janin ou P. de Musset, ou moins souvent cités comme l'abbé Gaume (1847-1848) ou la comtesse de La Grandville (1836).

2 L'imagination romantique a investi cette ville, qu'elle a transformée en territoire mythique ouvrant sur l'Orient et ses joyaux, ce qui allait nourrir le sentiment de l'écoulement $\mathrm{du}$ temps propre aux romantiques. Cette fascination atteignit parfois à «un véritable délire»: le voyageur n'est plus un simple observateur, mais un véritable visionnaire, tel Gautier devant Saint-Marc. Fascination esthétique qui a des origines historiques: du gouvernement de Venise, les romantiques, lecteurs de la monumentale histoire de Daru (1820), retiennent la longévité du pouvoir patricien -«Venise commença à Attila et finit à Bonaparte», Belin, 1843- reprenant d'ailleurs les thèmes que l'Encyclopédie avait traités dans ses articles «Venise», «Doge» et sur le fameux Conseil des Dix. La déchéance de la Sérénissime fut aussi pour eux, par exemple pour 
Stendhal et Gautier, un objet de réflexion: on aurait aimé qu'à ce propos - la Venise placée sous la coupe autrichienne- les espoirs de 1848 fussent plus longuement évoqués; il est vrai que deux pages de l'Italia de Gautier sur le tintamarre destiné à fêter l'empereur d'Autriche disent plus et mieux que de longs commentaires! (pp. 97-100).

3 Si la Venise du XIX ${ }^{\mathrm{e}}$ siècle a beaucoup perdu de sa splendeur, si elle n'est plus la ville la plus heureuse du monde, le fond de son caractère perdure: pour l'auteur de la Vie de Rossini, qui ne se faisait pas d'illusions sur «la prétendue république de Venise», elle reste néanmoins «le pays le plus gai, le plus naturel, le plus heureux de l'Europe», l'héritière du bonheur de vivre du Settecento. Tous les voyageurs s'accordent sur l'art de vivre vénitien, particulièrement sur les plaisirs des patriciens -la bourgeoisie est ignorée- et sur l'originalité du peuple qu'incarnent les gondoliers, souvent opposés aux lazzaroni napolitains. Bien que la Venise du XIX ${ }^{e}$ siècle se meure ou soit déjà morte, bien qu'elle ne soit plus la ville de l'art et des artistes, le spectre des fastes d'antan hante les mémoires. Plaisir mélancolique de la contemplation d'une agonie-«C'est par ce soleil éteint qu'il faut voir aujourd'hui cette ville éteinte», Houssaye, 1850- qui va s'exacerber à l'époque décadente, jusqu'à devenir l'obsession morbide d'un paradis perdu.

4 Dix chapitres précis et bien menés, ainsi qu'une riche bibliographie permettent d'évoquer ce miracle que le romantisme a marqué du sceau de la volupté et de la nostalgie. 